\title{
Designing more sustainable cities by integrating infrastructure systems
}

\author{
S. P. French \\ College of Architecture, Georgia Institute of Technology, USA
}

\begin{abstract}
Modern cities are supported by advanced infrastructure systems that supply them with energy and materials and dispose of their wastes. For centuries separate systems have been designed to provide the water supply, wastewater treatment, energy, stormwater management, solid waste disposal and transportation services needed by urban residents. As the majority of the world's population now lives in urban areas, most of the human impact on the natural environment is mediated through urban infrastructure systems. As the science and technology of infrastructure systems has advanced, they have become more and more isolated from each other. The performance of each system has been optimized independently but little attention has been given to the complex interactions among these infrastructure systems. There is mounting evidence that more sustainable cities can be designed by using a more holistic approach to infrastructure system design. This paper will provide an overview of this more holistic approach to infrastructure design. Specific examples of how more sustainable solutions can be achieved will be discussed to illustrate how understanding the interactions and synergies among urban infrastructure systems is key to creating more sustainable forms of urban growth. The paper will close with a discussion of ongoing research on developing an integrated understanding of infrastructure systems to support the planning and design of more sustainable cities.

Keywords: sustainable, infrastructure, urban metabolism, urbanization, urban systems, environmental impacts.
\end{abstract}

\section{Introduction}

In 2008 the earth crossed a significant tipping point. For the first time in human history, more than half of the world's population was living in cities. This is a relatively recent development in human settlement patterns. As shown in Table 1, 
the world's population has increased rapidly in the last two centuries and is becoming more and more urban. By 2050 the world population will have increased nearly tenfold from 1800 . The year 1800 provides a useful demarcation point because it roughly marks the beginning of the industrial revolution. At that time only 2 percent of the world's population lived in cities, and that had increased to just 14 percent by 1900 . The pace of population growth and urbanization has significantly intensified in the past century. More than 80 percent of the world population is expected to live in urban areas by 2050. With the vast majority of the greatly expanded population living in urban areas by mid-century, it is no wonder U.N. Secretary General Ban Ki-moon [1] has said, "Our struggle for sustainability will be won or lost in the cities."

Table 1: Percentage of world population living in urban areas.

\begin{tabular}{|c|c|c|}
\hline Year & World Population (in billions) & Percent Urban \\
\hline 1800 & 0.98 & 2 \\
\hline 1900 & 1.65 & 14 \\
\hline 2008 & 6.75 & 50 \\
\hline 2050 & 9.55 & 80 \\
\hline
\end{tabular}

Between now and 2050 the world's population is expected to grow by nearly 2.5 billion additional people. This is approximately the total population of the planet in 1950. Most of these new residents will live in urban areas. How they are housed and how their needs are met will determine how sustainable the future will be.

While urban areas now house the majority of the world's population, they consume surprisingly little land area. Only about 3 percent of the world's land mass is urban. For example, in the USA, land area classified as urban accounts for just 2.6 percent of the land area, yet contains nearly 80 percent of the population. European nations have the highest proportion of their land are in urban uses, with most containing between 10 percent and 30 percent urban land. However, the greatest wave of urbanization is occurring in China, India, and Africa, which are experiencing a massive population shift from rural areas to large urban areas. Because they are the focus of most economic activity, urban areas dominate resource consumption and waste generation.

Concentrating population into urban areas requires extensive infrastructure systems to provide the services necessary to support the needs of the population. Infrastructure systems are required to supply clean water, to treat household and industrial waste water, to manage storm water runoff, to provide energy and to move people and goods. This reliance on infrastructure systems fundamentally changes the relationship between humans and nature. People no longer interact with natural systems directly, as they would in a low density, rural settlement pattern. Their environmental impacts are almost entirely mediated through their infrastructure systems. How these systems are designed and operated largely 
determines how the population will impact the natural environment. While urban population is concentrated in a relatively small area, cities rely on resources drawn from a much larger area. Their waste materials are discharged back into the environment and can impact water, air and climate systems on a regional or even global scale.

\section{Urban metabolism}

Wolman [3] developed the concept urban metabolism to understand how cities consume material and energy. Urban metabolism considers a city as a large organism that takes in material and energy, produces the goods and services that residents require, and puts out wastes. Newman [4] extended this model to include the production of greenhouse gases. Baccini [5] suggests that urban metabolism can provide a useful framework to evaluate sustainability concerns.

Generally, the impact of human population on the natural environment is a function of three factors: (1) the size of the population, (2) the standard of living of that population and (3) the technology used by that population. Environmental impacts increase as population increases. Therefore, we can expect the amount of resources consumed and the volume of waste generated to increase with the size of the population. Similarly, populations with higher standards of living tend to consume more resources and produce more waste than those with lower standards of living. The role of technology is more complex. Different technologies have different input requirements and produce different amounts and types of waste. Different technologies also differ in terms of their overall efficiency. Therefore, different technologies have different demands for material and energy inputs. The selection of the technology used to provide a particular infrastructure service is a key in determining the material and energy inputs that will be required and the waste that will be produced to meet the needs of a given population with a given standard of living.

\section{Individual infrastructure systems}

The size of our infrastructure systems has needed to expand markedly to keep pace with the steadily increasing urban populations. Massive investments have been made to construct the urban infrastructure systems that support today's urban population. Along the way there have been incremental improvements in infrastructure system technology. In most cases these systems have become more efficient in terms of their material and energy demands and have become cleaner in terms of the amount of waste they generate. However, the massive increases in population and standards of living have tended to overwhelm these improvements in technology. While cities across the globe have made significant investments in new infrastructure systems, Nelson [6] notes that by 2050, the existing amount of urban infrastructure will have to double. This presents a huge challenge and as 
well as a unique opportunity. How we design this new increment of infrastructure will determine how sustainable our cities, and, therefore our planet, will be.

While cities across the globe have made significant investments in new infrastructure systems, Nelson [6] notes that by 2050, the existing amount of urban infrastructure will have to double to meet the increase in population and the continuing trend of urbanization. This presents a huge challenge, but also it is also a major opportunity. In the next 35 years we will build as much infrastructure as exists today. Building these systems in a way that has a smaller demand for material and energy inputs and generates less waste, will determine how sustainable our new urban future will be.

Over the past two centuries infrastructure systems have become more and more specialized over time. The professionals who design these systems and the agencies that own and manage them have become separated, so that each of the systems is designed and operated separately. The design and performance of each system is optimized separately, with little regard for how it interacts with the other infrastructure systems. Figure 1 illustrates the current situation in which each of these infrastructure systems operates as a separate "stovepipe."

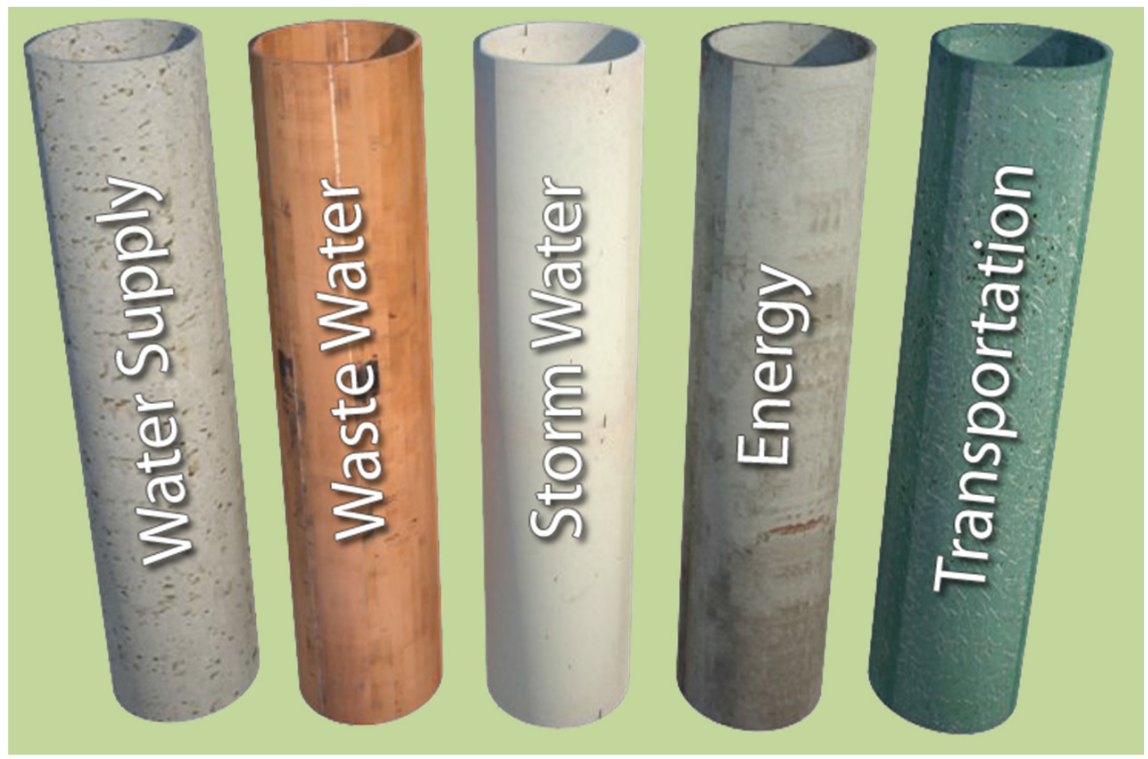

Figure 1: Current situation: infrastructure systems as separate stovepipes.

Designing and managing these systems separately ignores the complex interactions between and among these systems. They do in fact interact in significant ways. For example, to change to an electrified transportation system based on plug-in hybrids may require a significant increase in the amount of electricity generated. If this electricity is produced using coal or nuclear generation technology, a significant amount of water will be required for cooling these plants. 
Additional water withdrawals for power plant cooling may limit the amount of water available for domestic and industrial uses. Therefore, the technologies selected for the transportation system and for electric power generation directly impact the water supply system. Similarly, there are very few instances of utilizing the organic material in waste to produce energy. These types of crossinfrastructure relationships are rarely considered in the planning and design of urban infrastructure systems. As urban population continues to increase and puts more pressure on natural systems, more comprehensive planning and design will be required to take account of the complex interactions between and among urban infrastructure systems.

Today each infrastructure system is optimized as a separate system. These systems are the result of single objective design and spending. This approach misses significant opportunities to create more sustainable solutions to meet the needs of urban populations. By approaching the design and management of urban infrastructure in a more holistic fashion, we can take advantage of synergies that exist among these systems and create more sustainable infrastructure solutions.

\section{Integrated infrastructure systems}

Crittenden [7] has stated the problem clearly when he said, "We need to recreate the anthroposphere to exist within the means of nature. That is, use renewable resources that nature provides and generate waste nature can assimilate without overwhelming natural cycles." To create infrastructure systems that operate within the resources and assimilative capacity that nature provides, we need to consider infrastructure systems holistically and identify where the inputs and outputs of each system are likely to impact each other system.

The analysis of these system interactions a better understanding of the fundamental properties of each system so that the key inputs and outputs of that system can to be described and quantified where ever possible. To support the development of today's single purpose systems, robust infrastructure-specific simulation modeling tools have been developed in recent years. Today we have reasonable accurate water demand models, stormwater runoff models, wastewater treatment process models and transportation demand models. In most cases these models are very good at evaluating the performance of individual infrastructure systems. These models provide a good initial framework for identifying the inputs required by and the outputs produced by each individual infrastructure system. However, most of these models do not capture the complex interactions among infrastructure systems or between these systems and their associated social and natural systems.

It is important to note that these models often address only a single technology solution to meeting the infrastructure needs of an urban area. Separate models may be needed to understand the requirements of alternative technologies that can meet the same needs. For example, the material consumed and the type and amount of waste produced varies considerable between a coal-fired power plant and a distributed system of photovoltaic collectors. Today's simulation models are 
generally designed to address one particular technology and may not cover the full range of potential solutions. The result of this analysis should be to develop an interaction matrix that identifies the inputs and outputs of each system. Table 2 shows the major interactions that are expected among the major urban infrastructure systems. This matrix provides a framework for understanding the linkages among infrastructure systems much as an input/output matrix describes the interactions between industrial sectors in the economy.

Further research is needed to provide more detailed data on each type of interaction. The type and of material and energy exchanged between each system is needed to build a fully functional interaction model. Again, the nature and amounts of materials exchanged will vary with the specific technology chosen for each infrastructure type. Very little data exists on the size and scope of these interactions among infrastructure systems. Fortunately, as more and more of these systems are instrumented with sensor systems, rich data sets are being developed that will support detailed analysis to describe these interactions. Producing a quantified version of this type matrix is a fundamental task in understanding the complex interactions among infrastructure systems. A detailed interaction matrix is critical to understanding how to create more sustainable infrastructure systems. This will provide support for infrastructure decisions at a variety of scales, including evaluating metropolitan-scale urban form, testing alternative infrastructure technologies (e.g. distributed vs. centralized energy production and wastewater treatment) and analyzing project-level social and environmental impacts.

Table 2: Major interactions between infrastructure systems.

\begin{tabular}{|l|c|c|c|c|c|}
\hline & Water & Sewer & Stormwater & Energy & Transportation \\
\hline Water & & $\mathrm{X}$ & $\mathrm{X}$ & $\mathrm{X}$ & \\
\hline Sewer & $\mathrm{X}$ & & $\mathrm{X}$ & $\mathrm{X}$ & \\
\hline Stormwater & $\mathrm{X}$ & $\mathrm{X}$ & & & $\mathrm{X}$ \\
\hline Energy & $\mathrm{X}$ & $\mathrm{X}$ & & & $\mathrm{X}$ \\
\hline Transportation & & & $\mathrm{X}$ & $\mathrm{X}$ & \\
\hline
\end{tabular}

\section{The broader context}

Infrastructure systems do not exist in a vacuum. Figure 2 shows how these systems interact with both the natural environment and the social and economic systems that build and maintain them. As discussed above infrastructure systems mediate the impact of urban populations on the natural environment. They draw material and energy resources from the natural environment and emit waste material back into that environment. They have significant impacts on air and water quality, on aquatic habitats, on land and on mineral resources. 


\section{Natural Environment Systems}

AIR | WATER | HABITAT I LAND I MINERAL RESOURCES

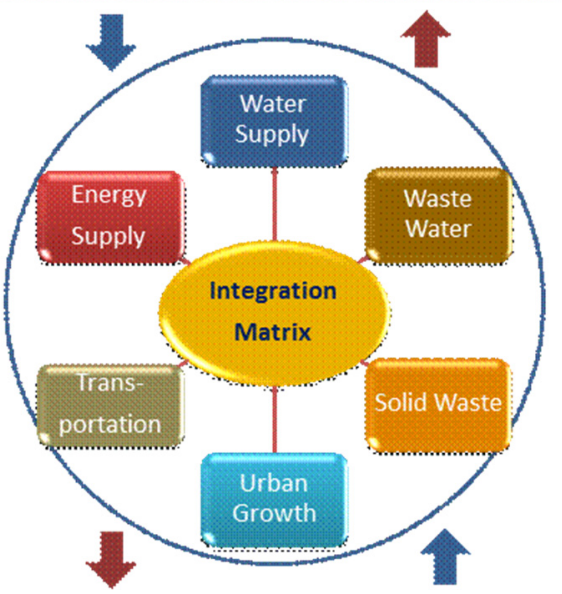

\section{Social and Economic Systems}

INCOME | HEALTH | EQUITY | ETHICS | SOCIAL STRUCTURE | POLICY

Figure 2: Infrastructure systems in context.

These systems are also shaped by and impact their larger social and economic system. The level and quality of service provided is determined by political and economic forces. There is a two way interaction between the infrastructure systems and the underlying social and economic systems. The quality of the infrastructure provided is determined by the income, ethics and policies of the society. But these systems in turn impact the income, health and equity of that society. So there is a dynamic two-way relationship between the social and economic systems and the infrastructure systems.

It is important to place these infrastructure systems within this larger context to understand the factors that shape their design and operation and to understand the broader set of impacts these systems have, not only on the natural environment, but also on human social and economic systems.

\section{Conclusions}

Infrastructure systems are critical to supporting the world's rapidly expanding urban population. These systems are currently optimized individually. This standalone approach produces suboptimal solutions for the larger urban system. More research is needed to understand the complex interactions among these systems and to account for their interactions with not only natural systems, but also social and economic systems. Such an approach is needed to produce solutions that are environmentally and economically sustainable as well as equitable. 


\section{References}

[1] Ki-moon. B. Press release. United Nations Department of Public Information, April 23, 2012.

[2] Abraham, R. Welcome to the urban century. WashingtonPost.com. posted online 1/29/2011, 10:28 am.

[3] Wolman, A. The metabolism of cities. Scientific American, 213(3), pp. 179-190, 1965.

[4] Newman, P. Sustainability and cities: extending the metabolism model. Landscape and Urban Planning, (44), pp. 219-226, 1999.

[5] Baccini, P. A city's metabolism: towards the sustainable development of urban systems. Journal of Urban Technology, 4(2), pp. 27-39, 2007.

[6] Nelson, A. C. Toward a New Metropolis: The Opportunity to Rebuild America. Washington, DC: The Brookings Institute, 2004.

[7] Crittenden, J. The gigaton problem: challenges and opportunities. International Conference on Engineering Science and technology. Beijing, China, June 2-3, 2014. 